\title{
Long noncoding RNA SNHG17: a novel molecule in human cancers
}

\author{
$\mathrm{Li} \mathrm{Ma}^{1 \dagger}$, Jin Gao ${ }^{1 \dagger}$, Niu Zhang ${ }^{1 \dagger}$, Jiawei Wang ${ }^{2 \dagger}$, Tianwei Xu' , Tianyao Lei ${ }^{1}$, Xiaoteng Zou ${ }^{1}$, Chenchen Wei ${ }^{{ }^{*}}$ and \\ Zhaoxia Wang ${ }^{1 *}$ (D)
}

\begin{abstract}
Many studies in recent years have found that dysregulation of long non-coding RNAs (IncRNAs) can contribute to disease. Small nucleolar RNA host gene 17 (SNHG17) is a novel cancer-related IncRNA of the SNHG family which is highly expressed in various tumors and may exert oncogenic functions. Several studies have demonstrated that SNHG17 is closely related to the proliferation, migration, invasion, apoptosis, and chemical drug resistance of tumor cells, and clinical studies have found an association between high SNHG17 expression and poor prognosis. In this review, we summarize relevant studies investigating SNHG17, focusing on its biological function as well as its potential value for clinical applications.
\end{abstract}

Keywords: SNHG17, IncRNA, Cancer, Gene regulation, Diagnosis, Prognosis

\section{Introduction}

The World Health Organization (WHO) GLOBOCAN 2020 data [1] reported 19.3 million new cancer cases as well as an estimated 10 million cancer deaths worldwide in 2020. These numbers are expected to rise further over the upcoming years, with epidemiologists predicting 34 million new cases worldwide by 2070 [2]. The economic cost related to treatment and nursing costs of cancer patients poses a significant socioeconomic burden and cancer represents a serious issue for human health and social welfare systems [3]. There is an urgent need to improve cancer prevention strategies and develop new early screening and treatment approaches which may help not only increase lifespan but also improve patients' quality of life and reduce the global socioeconomic burden of cancer.

*Correspondence: weichenchen1990@126.com; wangzhaoxia@njmu.edu.cn †Li Ma, Jin Gao, Niu Zhang and Jiawei Wang contributed equally to this work

${ }^{1}$ Cancer Medical Center, The Second Affiliated Hospital of Nanjing Medical University, Nanjing 210011, Jiangsu, China

Full list of author information is available at the end of the article
Long non-coding RNAs (lncRNAs) refer to RNAs of more than 200 bases in length that do not encode proteins, although some new reports [4] suggest that certain ncRNAs may encode micropeptides. In recent years, the small nucleolar RNA host gene (SNHG) family of lncRNAs [5-7] has been demonstrated to exert oncogenic features in various cancers. SNHGs have been found to be overexpressed in several cancer types and may be involved in proliferation, apoptosis, invasion, metastasis, drug resistance and other biological functions of cancer cells. Mechanistically, SNHGs have been reported to mediate their actions as competing endogenous RNAs (ceRNAs). CeRNAs were first described by Salmena et al. [8] in 2011 and correspond to a variety of RNA transcripts with microRNA (miRNA) response elements (MRE). When these transcripts sponge miRNA they can affect the binding of other transcripts to this miRNA, thus regulating the gene expression (9). As shown in our previous study, the LINC01234/miR-204-5p/CBFB axis promotes cells proliferation in gastric cancer (GC) [10].

Small nucleolar RNA host gene 17 (SNHG17), a 1186 nucleotide lncRNA, is a member of the SNHG family and located on human chromosome 20q11.23. original author(s) and the source, provide a link to the Creative Commons licence, and indicate if changes were made. The images or other third party material in this article are included in the article's Creative Commons licence, unless indicated otherwise in a credit line to the material. If material is not included in the article's Creative Commons licence and your intended use is not permitted by statutory regulation or exceeds the permitted use, you will need to obtain permission directly from the copyright holder. To view a copy of this licence, visit http://creativecommons.org/licenses/by/4.0/. The Creative Commons Public Domain Dedication waiver (http://creativeco mmons.org/publicdomain/zero/1.0/) applies to the data made available in this article, unless otherwise stated in a credit line to the data. 
Similar to other members of the SNHG family, it has been reported as an oncogene and can promote proliferation, invasion, migration, and angiogenesis while inhibiting apoptosis in tumors (Fig. 1). SNHG17 has several transcripts and has been shown to be expressed both in the nucleus and cytoplasm of different tumor cells via fluorescence in situ hybridization (FISH) or nucleo-cytoplasmic separation experiment [11, 12]. The first report on SNHG17 was published by Ma et al. [13] and found that SNHG17 overexpression in colorectal cancer promoted cell proliferation via epigenetic silencing of P57. SNHG17 has subsequently also been found to be overexpressed in lung cancer [14], GC [15], hepatocellular carcinoma [16], osteosarcoma [17, 18 ] and other tumors, and its expression levels have been reported to be associated with a poor prognosis. In addition, SNHG17 also performs unique biological functions in other diseases, such as gestational or type 2 diabetes mellitus $[19,20]$ and diabetic nephropathy [21]. The above results indicate that SNHG17 may play an essential pathogenic role in a variety of diseases, in particular cancers.
While many members of the SHNG family have been systematically reviewed in detail, including SNHG1 [22], SNHG3 [23], SNHG4 [24] and others [25-36], this has not been the case for SNHG17. Data from the Gene Expression Profiling Interactive Analysis 2 (GEPIA2) database indicated that SNHG17 exhibits high pan-cancer expression (Fig. 2). Combined with existing reports on SNHG17, here we summarize the tumor-promoting mechanisms and corresponding clinical significance of SNHG17 in some relative frequent cancer types, such as oral tumor, esophagus cancer, non-small cell lung cancer (NSCLC), breast cancer (BC), GC, colorectal cancer (CRC), hepatocellular carcinoma (HCC), pancreatic cancer, renal cell carcinoma, prostate cancer, ovarian cancer, glioma and melanoma.

\section{The role of SNHG17 in cancers}

Oral tumors

Oral tumors are highly malignant and have become increasingly prevalent in younger patients in recent years. The main treatment options include surgery, radiotherapy, and chemotherapy, which can further damage the

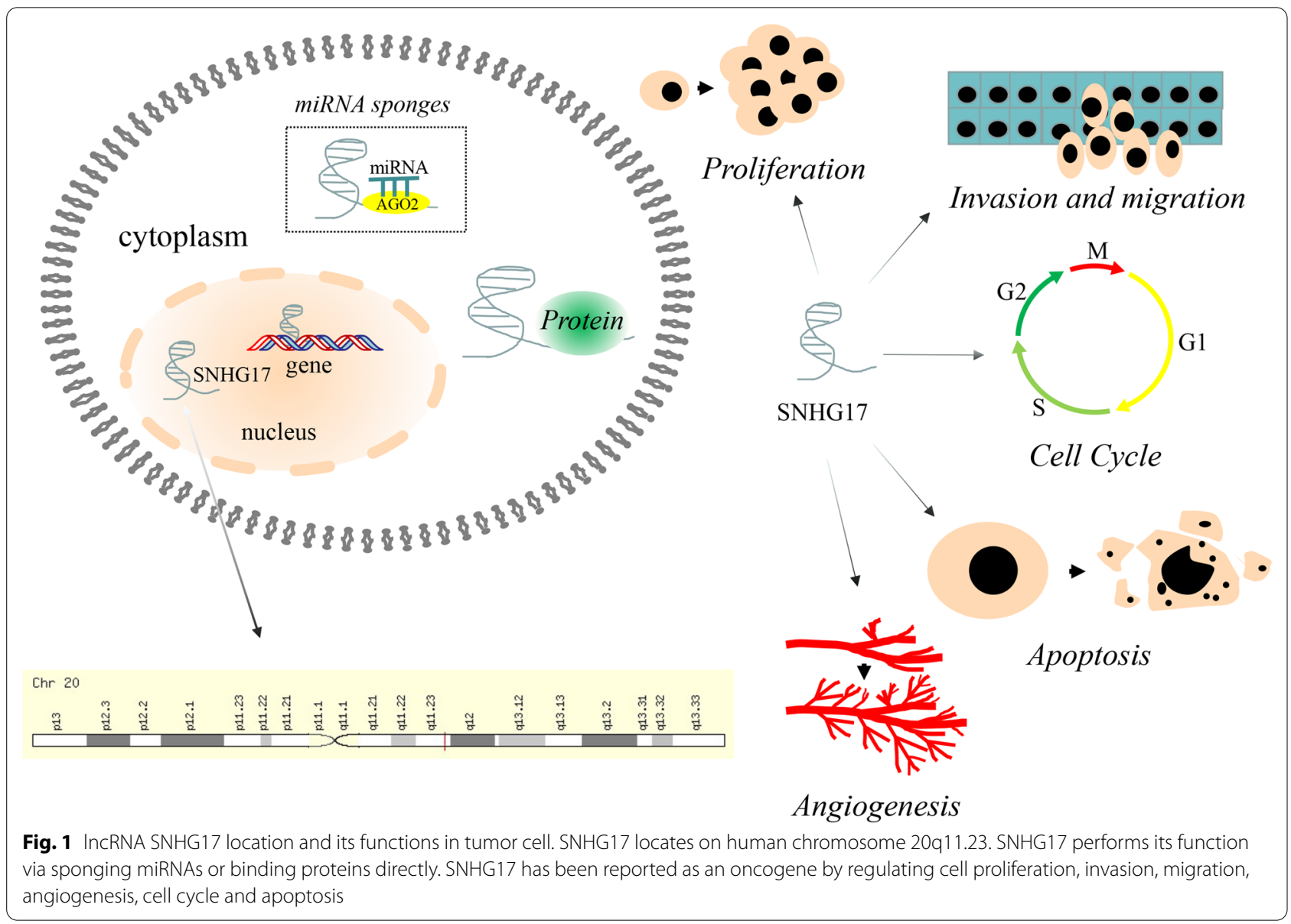




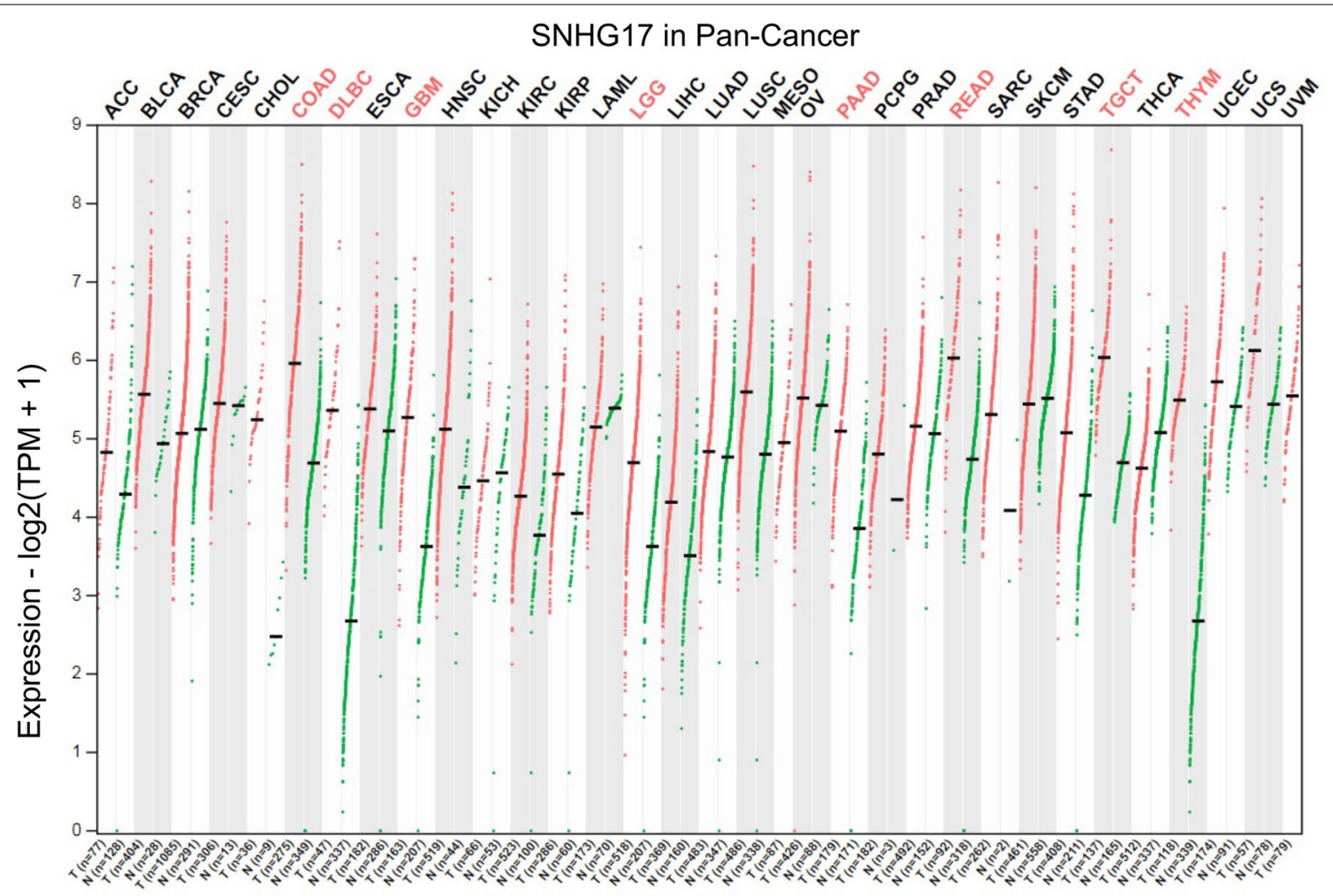

Fig. 2 IncRNA SNHG17 expression in various cancers. Data from GEPIA2 database indicates that SNHG17 overexpressed in various tumors, such as colon adenocarcinoma (COAD), esophageal carcinoma, pancreatic adenocarcinoma, rectum adenocarcinoma and so on

quality of life of patients [37]. The below studies indicate that SNHG17 may play an important role in oral tumors and therefore possesses an important clinical value for the diagnosis and treatment of oral tumors.

Oral squamous cell carcinoma (OSCC) is a highly malignant oral tumor. Without timely and effective treatment, it frequently leads to deformities and death. The 5-year survival rate of OSCC is $55 \%$, with a recurrence rate of $38 \%$ [38]. SNHG17 has been found to be significantly overexpressed both in OSCC cell lines [39] and clinical samples of OSCC patients compared to controls, and its expression levels were positively correlated with adverse pathological indicators [40]. Qiao et al. [39] investigated the biological mechanism of SNHG17 in OSCC through various techniques including RNA Binding Protein Immunoprecipitation (RIP), RNA pulldown, chromatin immunoprecipitation (ChIP), and luciferase reporter assay and so on, they reported that SNHG17 acted as a ceRNA of miR-384. SNHG17 sponged miR-384 to upregulate ELF1, a transcriptional activator of CTNNB1, This resulted in activation of the Wnt/ $\beta$-catenin signaling pathway and could promote the development and occurrence of OSCC. In line with these results, Tong et al. [40] revealed that overexpressed SNHG17 promoted the proliferation, migration, and invasion of OSCC cells while inhibiting their apoptosis, Mechanically, SNHG17 acted as a ceRNA of miR-375 and upregulated PAX6 to exert its carcinogenic role.

Tongue squamous cell carcinoma (TSCC) is the most common subtype of oral cancer. TSCC usually leads to masticatory and speech dysfunction and dysphagia, seriously affecting the quality of life of patients [41]. The incidence and mortality of TSCC in China have been reported to be $4.81 \%$ and $2.21 \%$, respectively [42]. Quantitative real-time quantitative polymerase chain reaction (qRT-PCR) analysis of 56 paired TSCC and adjacent normal tissues indicated that SNHG17 was highly expressed in TSCC tissues. Its expression was furthermore positively correlated with advanced tumour-node-metastasis (TNM) stages and shorter overall survival (OS) [41]. Liu et al. [41] revealed that SNHG17 promoted cells proliferation, migration, and invasion of TSCC tumor cells in vitro as well as tumor metastasis in vivo, by sponging miR-876 and subsequent upregulation of SP1.

\section{Esophagus cancer}

Esophagus cancer is a common gastrointestinal tumor [1]. Esophageal squamous cell carcinoma (ESCC) accounts for approximately $90 \%$ of esophageal cancers in China [43], and its 5-year survival rate lies 
below 30\% [44]. Chen et al. [45] found that SNHG17 was upregulated in 126 carcinoma tissues compared to adjacent non-cancerous tissues, the same result in cells. Their analysis [45] also revealed that SNGH17 promoted epithelial-mesenchymal transition (EMT) progress, proliferation and invasion of ESCC cells by sponging miR-338-3p, thereby activating SOX4, These data suggested that SNHG17 accelerates ESCC progression through miR-338-3P/SOX4 pathways.

\section{Non-small cell lung cancer}

Lung cancer is a major contributor to new cancer cases and deaths, and poses a serious threat to human health [46], around 85\% of them is NSCLC [47]. SNHG17 was reported to be upregulated in both NSCLC tissues and cell lines [14, 48, 49] and associated with advanced TNM stage and shorter OS [49]. SNHG17 knockdown has moreover been found to inhibit NSCLC cell proliferation, migration, invasion and EMT progress, while promoting cell apoptosis in vitro. Our group [14] previously revealed that high expression of SNHG17 in NSCLC was a result of gene amplification. Gene expression analysis in SNHG17 knockdown cells revealed that SNHG17 inhibits FOXA1 while upregulating XAF1 and BIK, three genes closely related to cell proliferation and apoptosis. Researches from other groups moreover found that high SNHG17 expression promotes lung adenocarcinoma (LUAD) cell proliferation, migration and invasion via sponging miR-485-5p [48] and miR-193a-5p [49]. The authors concluded that SNHG17 promotes LUAD development via the miR-485-5p/WLS [48] and miR-193a-5p/NETO2 [49] pathways. Taken together, these studies suggest an important role for SNHG17 in regulating proliferation, migration and invasion in NSCLC, and it may represent a potential target for diagnosis and treatment to NSCLC.

\section{Breast cancer}

According to the latest statistical data [1], BC has now surpassed lung cancer as the cancer with the highest incidence, and it also represents the main cause of cancer deaths worldwide. Using qRT-PCR, Du et al. [12] assessed that SNHG17 is also upregulated in BC tissues and cells compared with controls, their data also suggested that upregulated SNHG17 predicts advanced TNM stages and lower survival time for patients with BC. In their research, SNHG17 expedites BC cell proliferation, migration, and invasion by targeting miR$485-5 p$, but further research is required to elucidate the exact mechanisms of action of SNHG17 in BC.

\section{Gastric cancer}

$\mathrm{GC}$ is a common malignant tumor with more than 1 million new cases worldwide each year. Unfortunately, most patients are diagnosed with advanced stages at the first clinical visit and the median survival of advanced patients treated with chemotherapy is less than one year [50]. There is an urgent need for new, accurate, and convenient detection techniques to diagnose GC at early stages.

Studies revealed that SNHG17 is significantly upregulated in both GC tissues [15, 51] and cells [15]. Data by Chen et al. [51] suggested that high expression of SNHG17 is not only positively correlated with advanced TNM stages, lymph node metastasis, and distant metastasis, but also negatively correlated with progression-free survival (PFS) and OS in GC patients. Multivariate analyses suggested that SNHG17 might serve as an independent prognostic marker for GC. Zhang et al. [15] found that SNHG17 expression levels has a high diagnostic value for $\mathrm{GC}$, with an area under the receiver operating characteristic $(\mathrm{ROC})$ curve $(\mathrm{AUC})$ of $0.748(\mathrm{P}<0.001)$. In their report [15], SNHG17 depletion inhibited cell proliferation, arrested the cell cycle in the G0/G1 phase, promoted apoptosis, and suppressed cell migration and invasion both in vitro and vivo. Mechanistically, SNHG17 acted as an oncogene in GC by epigenetically silencing $p 15$ and $p 57$ via activation of EZH2.

Helicobacter pylori (HP) infection is thought to be the main cause of gastric cancer [50]. Using a lncRNA microarray, Han et al. [11] identified SNHG17 closely related to HP-infected gastric, its expression was gradually increased with increased gastric mucosal lesion degree. Mechanically, SNHG17 knockdown reduced the level of DNA double-strand breaks (DSBs) following HP infection via binding to NONO, a molecule which could upregulate the expression of the DNA damage repair protein Ku80. The authors [11] additionally revealed that SNHG17 could alter the DNA repair system via SNHG17-miR-3909-RING1/Rad51 axis in GC. Taken together, these results indicate that SNHG17 acts as an oncogene in GC and could represent a novel biomarker for its diagnosis, treatment, and prognosis.

\section{Colorectal cancer}

CRC is a malignant tumor with high morbidity and mortality, accounting for approximately $10 \%$ of new cases and deaths per year [1]. About 20\% of CRC patients present with distant metastasis at the time of diagnosis, most of which are found in the liver and lung. The 5-year survival rate of metastatic CRC patients is only $14 \%$, and surgical treatment or systemic therapy offer little survival benefit to patients [52]. It is therefore particularly urgent to 
explore the pathogenesis and identify novel targets for early diagnosis and treatment.

Data from Gene Expression Omnibus (GEO) (GSE21510) [13], Encyclopedia of RNA Interactomes (ENCORI) and GEPIA databases [53] suggests that SNHG17 is highly expressed in CRC tissues. Further evidence for an upregulation of SNHG17 in CRC stems from qRT-PCR analysis in CRC tissues from clinical tissue samples $[13,53,54]$ or CRC cells [13, 53-55]. SNHG17 expression is also positively correlated with tumor size and TNM stages, while it is negatively correlated with CRC prognosis [13]. High SNHG17 expression may accelerate CRC cell proliferation, invasion, migration and inhibit apoptosis. SNHG17 has been reported to function as miRNA sponges of miR-375 [53], miR-23a-3p [55], miR-361-3p [54]. Liu et al. [53] demonstrated the role of miR-375 in CRC, they illustrated that miR-375, a direct target of SNHG17, could reverse the inhibitory effect of SNHG17 knockdown on EMT progression by targeting CBX3. In Huang's study [54], they suggested that SNHG17 sponges miR-361-3p to upregulate STC2, which is considered to promote proliferation of CRC cells. While Liu's report [55] showed that SNHG17 could ptomote the metastasis of CRC via sponging miR23a-3p, inducing an upregulated expression of CXCL12, a molecule which could regulate tumor angiogenesis. In addition, Ma et al. [13] proved that SNHG17 could epigenetically silence p57 transcription via interaction with EZH2 in CRCs.

Via several experimental approaches, the above studies propose SNHG17 as an oncogene in CRC. At the same time, SNHG17 may have an important clinical value for the prediction of prognosis. Therefore, SNHG17 may not only represent a novel target for CRC treatment but could also be employed for diagnosis and prognostic assessment.

\section{Hepatocellular carcinoma}

Liver cancer is the third leading cause of cancer deaths globally [1]. HCC is the major type of liver cancer, accounting for approximately $90 \%$ of liver cancers globally [56] and nearly 50\% of liver cancer cases in China [57]. This discrepancy is likely related to a high burden of chronic hepatitis in China [58]. Several studies previously assessed levels of SNHG17 in human HCCs and adjacent normal tissues via qRT-PCR $[16,59,60]$ and found a significant upregulation of SNHG17 in cancer tissues. Ma et al. [16] showed that overexpressed SNHG17 promoted the proliferation, migration, invasion and EMT progression of HCC cells. Mechanistic research demonstrated that SNHG17 regulates the miR-3180-3p/RFX1 axis. Meanwhile, Liu et al. [59] found that SNHG17 could combine with LRPRC to decrease the levels of ubiquitylated c-Myc and increase the stability of c-Myc protein, promoting cellular G1/S transition and enhancing cell proliferation.

\section{Pancreatic cancer}

Pancreatic cancer is known for its high malignancy and poor prognosis. Due to its particular anatomical site, early detection remains relatively challenging [61]. High expression of SNHG17 and low expression of miR-942 in pancreatic cancer tissues and cells was discovered by Zhao et al. [62]. Their data revealed that SNHG17 knockdown significantly depressed cell proliferation, viability, migration and invasion, while facilitating apoptosis, this effect could be reversed following overexpression of miR942. Further research into the target genes of miR-942 will be required to fully elucidate the role of SNHG17 and miR-942 in pancreatic cancer.

\section{Renal cell carcinoma}

Using data from The Cancer Genome Atlas (TCGA) database, Xuan et al. [63] proposed that SNHG17 functions as a regulator of autophagy by regulating ATG4B and CAPN10, although they do not perform any functional experiments. Wu et al. [64] found the higher expression of SNHG17 in renal cell carcinoma tissues and cells compared with controls via qRT-PCR. SNHG17 knockdown significantly inhibited the proliferation, migration, and invasion of tumor cells. The authors reported that SNHG17 may regulate H2AX signaling via miR-328-3p in renal cell carcinoma.

\section{Prostate cancer}

While the incidence of prostate cancer remains high [1], fortunately mortality rates are decreasing year by year [65]. Nonetheless, many patients experience post-treatment sequelae which can seriously affect their quality of life. The exploration and transformation of precise early diagnostic strategies and therapeutic targets are therefore critical.

Reports [66, 67] suggested that SNHG17 is significantly upregulated in both prostate cancer tissues and cells, especially in aggressive and metastatic cells [66]. Moreover, SNHG17 expression is negatively associated with prognosis. In Zhao's research [66], SNHG17 knockdown inhibited cellular proliferation, invasion, and chemotherapeutic resistance, while facilitating apoptosis. Mechanistic studies indicated that SNHG17 may regulate prostate cancer development via the $\mathrm{Wnt} / \beta$-catenin pathway. Wu et al. [67] showed that SNHG17 could upregulate its cognate small nucleolar RNA (snoRNA) SNORA71B and thereby promote the proliferation, invasion, migration, and EMT of prostate cancer cells, while inhibiting apoptosis. Mechanistic research suggested that 
both SNHG17 and SNORA71B transcription was activated by STAT5A. SNHG17 could in turn upregulate the expression of STAT5A by sponging miR-339-3p, thereby affecting SNORA71B expression in a positive feedback loop. In addition, Bai et al. [68] discovered higher expression levels of SNHG17 in tissues from castration resistant prostate cancer (CRPC) than in hormone sensitive prostate cancer (HSPC). Functionally and mechanically, SNHG17 promotes cell proliferation, migration and invasion by competitive binding of miR-144 and upregulation of CD51 in CRPC.

\section{Ovarian cancer}

Ovarian cancer is a common female tumor with an extremely poor prognosis. Unfortunately, a majority of patients relapse after treatments [69]. Studies on effective diagnostic and prognostic markers may help to improve patient survival.

SNHG17 is highly expressed in ovarian cancer tissues and cells [70, 71]. A study investigating data [72] from the TCGA database identified SNHG17 as an autophagyrelated gene in ovarian cancer. Moreover, increased SNHG17 expression was associated with shorter OS. In Pan's study [70], SNHG17 has further been found to suppress apoptosis and promote ovarian cancer cell proliferation in vitro and vivo. Mechanically, transcription factor STAT3 directly binds to the promoter region of SNHG17 and promotes its transcription, and SNHG17 subsequently regulates cell cycle progression and proliferation of ovarian cancer cells via the miR-214-3p/CDK6 axis. Zheng et al. [71] observed that both SNHG17 and FOXA1 are upregulated in ovarian cancer consistently. Functionally, SNHG17 knockdown dampened the proliferative and invasive abilities of cancer cells via partial downregulation of FOXA1. However, the specific mechanism by which SNHG17 regulates FOXA1 remains to be clarified.

\section{Cervical cancer}

Cao et al. [73] reported a high expression of SNHG17 in cervical cancer cells and serum of cervical cancer patients. SNHG17 knockdown significantly depressed proliferation, migration and invasion while facilitating apoptosis of cervical cancer cells. This effect could be reversed by overexpressing miR-375-3p.

\section{Glioma}

Gliomas are the most common primary malignant tumors of the brain. Unfortunately, most patients have an extremely poor prognosis [74], with the exception of circumscribed glioma patients which can be cured by surgical resection. Due to the blood-brain barrier and other factors, chemical drug treatment for gliomas remains difficult and novel therapeutics are required.

Analysis of the GEPIA database [75, 76] revealed a significant upregulation of SNHG17 in glioma compared to control samples. The expression of SNHG17 was moreover found to be negatively associated with OS. Additional studies [75-77] revealed that SNHG17 is highly expressed in both glioma tissues and cell lines, and its expression is associated with malignant features of gliomas. Functional experiments $[75,76]$ showed that SNHG17 knockdown significantly inhibited the proliferation, migration, and invasion of glioma cells, while promoting apoptosis. Mechanically, Ge et al. [75] proposed that SNHG17 exerts its carcinogenic role via the miR-23b-3p/ZHX1 axis in glioma. Another study by $\mathrm{Li}$ et al. [76] suggested that transcription factor YY1 directly binds to the promoter region of SNHG17 and enhances its transcription. SNHG17 subsequently regulates cell proliferation of glioma cells via the miR-506-3p/ CTNNB1/Wnt/ $\beta$-catenin signaling pathway. In addition, $\mathrm{Du}$ et al. [77] proposed that SNHG17 could regulate cell proliferation and stemness via the miR-876-5p/ERLIN2 axis in astrocytoma.

\section{Melanoma}

Using qRT-PCR analysis, Gao et al. [78] found that SNHG17 is highly expressed in both melanoma tissues and cell lines. SNHG17 upregulation is positively correlated with lymph node metastasis and decreased OS in melanoma patients, and SNHG17 expression is an independent predictor of melanoma prognosis. Functional studies confirmed that SNHG17 knockdown resulted in significantly reduced proliferation, migration, and invasion of melanoma cells. Mechanistic studies indicated that STAT3-induced upregulation of SNHG17 contributed to melanoma progression by promoting PI3K-AKT signaling.

\section{Conclusion}

While several strands of evidence [63, 79-81] propose that certain ncRNAs may encode micropeptides, the majority of ncRNAs reported to participate in physiological processes do not have the ability to encode proteins [82]. LncRNAs have been widely reported to show abnormal expression in human diseases, in particular in malignant tumors, and they have been suggested to play an important regulatory role in the occurrence, progression, and metastasis of tumors [83]. In this review, we focused on a novel lncRNA from SNHG family, SNHG17, which has been found to be highly expressed in various tumors. SNHG17 has been demonstrated to exhibit a high capacity to modulate the expression of specific targets closely associated with tumor cell proliferation, apoptosis, 
Table 1 Functional characteristics of SNHG17 in various cancers

\begin{tabular}{|c|c|c|c|c|c|c|}
\hline Cancer Types & Expression & Roles & Assessed Cell Lines & Phenotypes Affected & Related Genes & References \\
\hline $\begin{array}{l}\text { Oral squamous cell } \\
\text { carcinoma }\end{array}$ & UP & Oncogenic & YD-38, SCC-9 & $\begin{array}{l}\text { Proliferation, cell viability, } \\
\text { apoptosis }\end{array}$ & $\begin{array}{l}\text { miR-384, ELF1, CTNNB1, } \\
\text { Wnt/ } \beta \text {-catenin }\end{array}$ & [39] \\
\hline $\begin{array}{l}\text { Oral squamous cell } \\
\text { carcinoma }\end{array}$ & UP & Oncogenic & Tca8113, CAL-27 & $\begin{array}{l}\text { Proliferation, invasion, } \\
\text { migration, apoptosis }\end{array}$ & MiR-375, PAX6 & [40] \\
\hline $\begin{array}{l}\text { Tongue squamous cell } \\
\text { carcinoma }\end{array}$ & UP & Oncogenic & Tca8113, CAL-27 & $\begin{array}{l}\text { Proliferation, invasion, } \\
\text { migration, xenograft } \\
\text { growth }\end{array}$ & MiR-876, SP1 & [41] \\
\hline $\begin{array}{l}\text { Esophageal squamous } \\
\text { cell carcinoma }\end{array}$ & UP & Oncogenic & TE-1, Eca109 & $\begin{array}{l}\text { Proliferation, invasion, } \\
\text { EMT, xenograft growth }\end{array}$ & MiR-338-3p, SOX4 & [45] \\
\hline $\begin{array}{l}\text { Non-small cell lung } \\
\text { cancer }\end{array}$ & UP & Oncogenic & A549, PC9 & $\begin{array}{l}\text { Proliferation, migration, } \\
\text { apoptosis }\end{array}$ & FOXA1, XAF1, BIK & [14] \\
\hline Lung adenocarcinoma & UP & Oncogenic & A549, H1299 & $\begin{array}{l}\text { Proliferation, migration, } \\
\text { invasion, apoptosis }\end{array}$ & $\begin{array}{l}\text { Caspase-3, Bax, BCl-2, miR- } \\
\text { 485-5p, WLS }\end{array}$ & [48] \\
\hline Lung adenocarcinoma & UP & Oncogenic & A549, H1299 & $\begin{array}{l}\text { Proliferation, migration, } \\
\text { invasion, EMT }\end{array}$ & MiR-193a-5p, NETO2 & [49] \\
\hline Breast cancer & UP & Oncogenic & MCF-7, MDA-MB-231 & $\begin{array}{l}\text { Proliferation, migration, } \\
\text { invasion }\end{array}$ & miR-124-3p & [12] \\
\hline Gastric cancer & UP & Oncogenic & GES-1, SGC-7901, AGS & Repair of DNA damage & $\begin{array}{l}\text { NONO, Ku80, miR-3909, } \\
\text { Rad51, RING1 }\end{array}$ & [11] \\
\hline Gastric cancer & UP & Oncogenic & AGS, HGC-27, SGC-7901 & $\begin{array}{l}\text { Proliferation, invasion, } \\
\text { migration, cell cycle, } \\
\text { apoptosis, xenograft } \\
\text { growth }\end{array}$ & $\mathrm{EZH} 2, \mathrm{P} 15, \mathrm{P} 57$ & [15] \\
\hline Colorectal cancer & UP & Oncogenic & DLD-1, HCT116 & $\begin{array}{l}\text { Proliferation, cell viability, } \\
\text { cell cycle, apoptosis, } \\
\text { xenograft growth }\end{array}$ & $\mathrm{EZH} 2, \mathrm{P} 57$ & [13] \\
\hline Rectal cancer & UP & Oncogenic & SW837, SW1463 & $\begin{array}{l}\text { Proliferation, apoptosis, } \\
\text { xenograft growth }\end{array}$ & MiR-361-3p, STC2 & [54] \\
\hline Colon adenocarcinoma & UP & Oncogenic & HT29, Т84 & $\begin{array}{l}\text { Proliferation, invasion, } \\
\text { migration, EMT, xenograft } \\
\text { growth }\end{array}$ & $\begin{array}{l}\text { MiR-375, CBX3, } \\
\text { E-cadherin, Vimentin, } \\
\text { N-cadherin }\end{array}$ & [53] \\
\hline $\begin{array}{l}\text { Colorectal adenocarci- } \\
\text { noma }\end{array}$ & UP & Oncogenic & RKO, HCT116 & $\begin{array}{l}\text { Proliferation, migration, } \\
\text { cell viability, angiogenesis }\end{array}$ & MiR-23a-3p, CXCL12 & {$[55]$} \\
\hline Hepatocellular carcinoma & UP & Oncogenic & HepG2, Huh7 & $\begin{array}{l}\text { Proliferation, invasion, } \\
\text { migration, EMT, xenograft } \\
\text { growth, lung metastasis }\end{array}$ & $\begin{array}{l}\text { E-cadherin, Vimentin, } \\
\text { miR-3180-3p, RFX1 }\end{array}$ & [16] \\
\hline Hepatocellular carcinoma & UP & Oncogenic & $\begin{array}{l}\text { HepG2, SF, SNU-449, } \\
\text { HCCLM9 }\end{array}$ & $\begin{array}{l}\text { Proliferation, cell cycle, } \\
\text { xenograft growth, DNA } \\
\text { replicating }\end{array}$ & $\begin{array}{l}\text { LRPRC, c-MYc, ppRb, } \\
\text { CDK2, CDK4 }\end{array}$ & [59] \\
\hline Hepatocellular carcinoma & UP & Oncogenic & $\begin{array}{l}\text { PLC, SMMC-7721, Нер3B, } \\
\text { HuH-7 }\end{array}$ & $\begin{array}{l}\text { Proliferation, migration, } \\
\text { apoptosis }\end{array}$ & ERH, TBCA, TDO2, PDK4 & {$[60]$} \\
\hline Pancreatic cancer & UP & Oncogenic & PANC-1, AsPC-1 & $\begin{array}{l}\text { Proliferation, cell viability, } \\
\text { invasion, migration, apop- } \\
\text { tosis, xenograft growth }\end{array}$ & $\begin{array}{l}\text { Caspase-8, Bak, PPARY, } \\
\text { VEGF, ZEB1, BMP, ISG12a, } \\
\text { GDNF }\end{array}$ & {$[62]$} \\
\hline Prostate cancer & UP & Oncogenic & C4-2, LNCaP & $\begin{array}{l}\text { Proliferation, cell viability, } \\
\text { invasion, apoptosis, xeno- } \\
\text { graft growth, chemother- } \\
\text { apeutic resistance }\end{array}$ & Caspase- $3, \beta$-actin, TCF & {$[66]$} \\
\hline Prostate cancer & UP & Oncogenic & $P C-3, V C a P$ & $\begin{array}{l}\text { Proliferation, invasion, } \\
\text { migration, EMT, apopto- } \\
\text { sis, xenograft growth }\end{array}$ & $\begin{array}{l}\text { SNORA71B, STAT5A, } \\
\text { E-cadherin, N-cadherin }\end{array}$ & {$[67]$} \\
\hline $\begin{array}{l}\text { Castration-resistant pros- } \\
\text { tate cancer }\end{array}$ & UP & Oncogenic & $C 4-2, P C-3$ & $\begin{array}{l}\text { Proliferation, invasion, } \\
\text { migration, xenograft } \\
\text { growth }\end{array}$ & MiR-144, CD51 & {$[68]$} \\
\hline Renal cell carcinoma & UP & Oncogenic & $\mathrm{ACHN}, 786-\mathrm{O}$ & $\begin{array}{l}\text { Proliferation, invasion, } \\
\text { migration, cell viability, } \\
\text { apoptosis, xenograft } \\
\text { growth }\end{array}$ & MiR-328-3p, H2AX & {$[64]$} \\
\hline
\end{tabular}


Table 1 (continued)

\begin{tabular}{|c|c|c|c|c|c|c|}
\hline Cancer Types & Expression & Roles & Assessed Cell Lines & Phenotypes Affected & Related Genes & References \\
\hline Ovarian cancer & UP & Oncogenic & OVCAR-3, PEO1 & $\begin{array}{l}\text { Proliferation, cell cycle, } \\
\text { apoptosis, xenograft } \\
\text { growth }\end{array}$ & $\begin{array}{l}\text { STAT3, CTNNB1, miR- } \\
\text { 214-3p, CDK6 }\end{array}$ & [70] \\
\hline Ovarian cancer & UP & Oncogenic & OVCAR-3, SKOV3 & Proliferation, invasion & FOXA1 & [71] \\
\hline Cervical cancer & UP & Oncogenic & SiHa, HeLa & $\begin{array}{l}\text { Proliferation, invasion, } \\
\text { migration, apoptosis }\end{array}$ & MiR-375-3p & {$[86]$} \\
\hline Glioma & UP & Oncogenic & LN229, U251 & $\begin{array}{l}\text { Proliferation, invasion, } \\
\text { migration }\end{array}$ & MiR-23b-3p, ZHX1 & [74] \\
\hline Glioma & UP & Oncogenic & U87, U251 & $\begin{array}{l}\text { Proliferation, cell viability, } \\
\text { apoptosis, xenograft } \\
\text { growth }\end{array}$ & $\begin{array}{l}\text { Caspase3, Caspase9, Bax, } \\
\text { YY1, miR-506-3p, CTNNB1, } \\
\text { Wnt/ } \beta \text {-catenin }\end{array}$ & [75] \\
\hline Astrocytoma & UP & Oncogenic & LN215, U138 & $\begin{array}{l}\text { Proliferation, invasion, } \\
\text { migration, stemness, } \\
\text { chemotherapeutic resist- } \\
\text { ance }\end{array}$ & MiR-876-5p, ERLIN2 & [76] \\
\hline Melanoma & UP & Oncogenic & $\mathrm{CHL}-1, \mathrm{~A} 375$ & $\begin{array}{l}\text { Proliferation, invasion, } \\
\text { migration }\end{array}$ & $\begin{array}{l}\text { Caspase3, Caspase9, } \\
\text { STAT3, PI3K/AKT }\end{array}$ & [77] \\
\hline Osteosarcoma & UP & Oncogenic & CAFs, HOS, SJSA-1 & $\begin{array}{l}\text { Proliferation, } \\
\text { migration,apoptosis, } \\
\text { xenograft growth }\end{array}$ & MiR-2861, MMP2 & [18] \\
\hline
\end{tabular}

invasion, migration, amongst others (Table 1). These roles in tumor progression are mediated via a variety of molecular mechanisms frequently related to ceRNA regulation (Fig. 3). For example, SNHG17 exerts a protumor effect in CRC by sponging miR-23a-3p and upregulating CXCL12 [55]. In addition, SNHG17 can combine with LRPRC to decrease the levels of ubiquitylated c-Myc in order to promote cell proliferation [59]. We speculate there may be additional molecular mechanisms related to the action of SNHG17 in tumorigenesis, including methylation [84], acetylation [85], ubiquitination [59, 86], and other epigenetic modifications waiting to be explored.

\section{Future perspectives}

SNHG17 may possess a substantial value for clinical applications as its expression levels are frequently found to be correlated with tumor size, TNM stages, lymph node metastasis, distant metastasis, and chemical drug resistance (Table 2). In addition, SNHG17 may exhibit potential for early diagnosis in cancers. For instance, SNHG17 can be used to diagnose GC with AUC of 0.748 $(\mathrm{P}<0.001)[15]$, Additionally, the sensitivity and specificity of SNHG17 serum levels for the diagnosis of cervical cancer are $84.7 \%$ and $78.2 \%$ respectively [73].
In recent years, exosomes [87] have gained increasing interest as mediators of intercellular communication. Exosomes can transport proteins and nucleic acids between cells, several studies [88-90] have demonstrated that tumor-derived exosomes could represent diagnostic, prognostic, or predictive cancer biomarkers, with clinical studies to further explore this currently ongoing. A variety of previous studies have shown that lncRNAs secreted by exosomes can be used for early diagnosis of tumors. For instance, lncRNA-GC1 [91], lncRNA-UEGC1 [92], and lncRNAHOTTIP [93] found in circulating exosomes could be used to detect early-stage GC, while lncRNA-HOTAIR [94] derived from serum exosomes may serve as novel diagnostic and prognostic biomarker in glioblastoma multiforme. Interestingly, a recent study investigating SNHG17 [18] revealed that exosomal SNHG17 from carcinoma-associated fibroblasts promoted the proliferation and metastasis of osteosarcoma via the miR2861/MMP2 axis. Therefore, we speculate there may be additional scenarios where tumor-derived exosomes containing SNHG17 are involved in enhancing tumor progression or metastasis. 


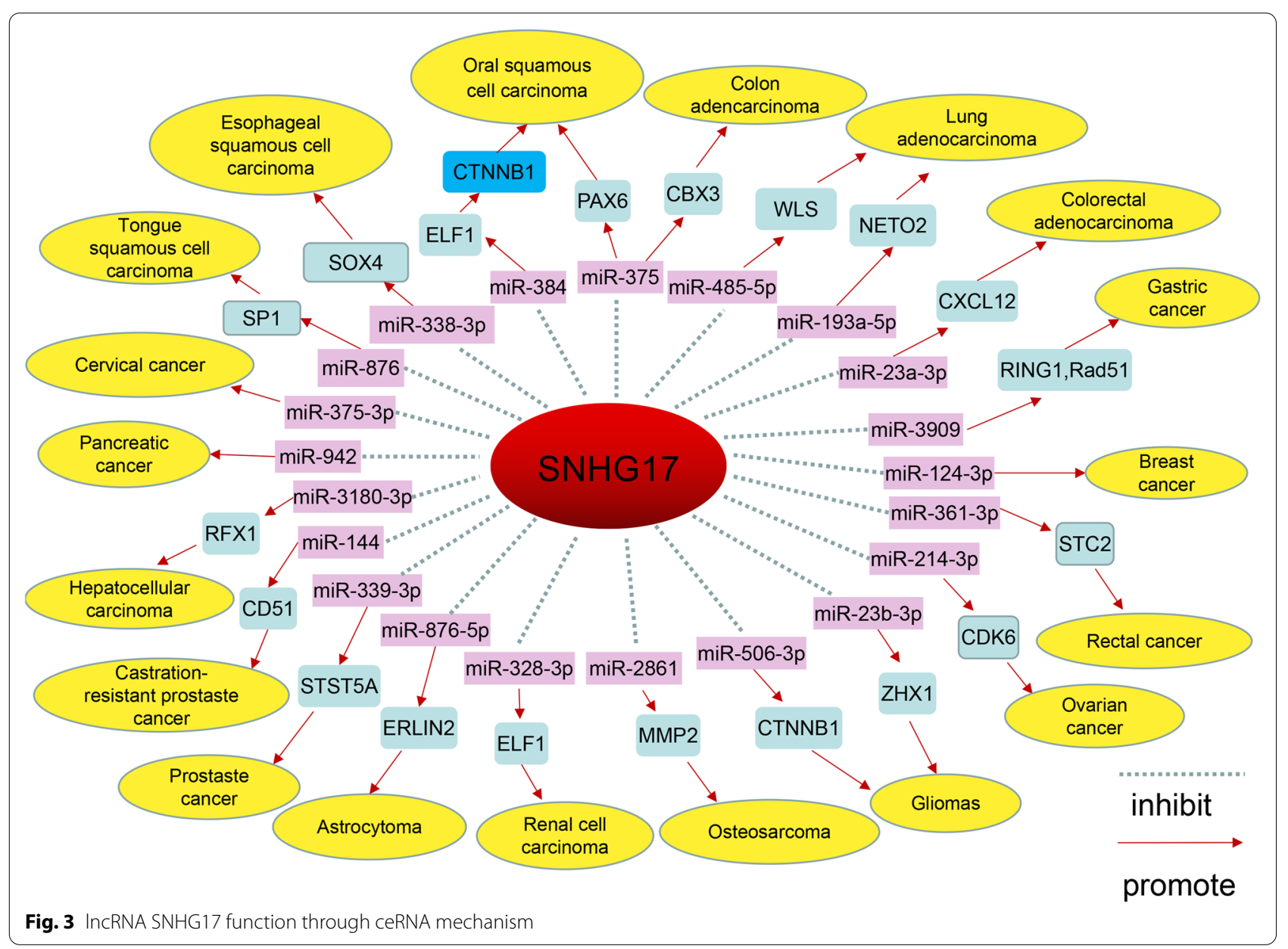

Therapies targeting ncRNAs, including antisense oligonucleotides (ASOs), small interfering RNAs (siRNAs), short hairpins RNAs (shRNAs), and CRISPRCas9-based gene therapy, have been of great interest for clinical management of cancers, and multiple therapies have already been approved by U.S. Food and Drug Administration (FDA) or European Medicines Agency (EMA) [95]. SNHG17 could be a future target for ncRNA-based pan-cancer therapies. In this review, we reported on the aberrant expression of SNHG17 in various cancers. Evidence to date suggests that SNHG17 plays an important role in tumorigenesis and has potential for clinical applications in tumor diagnosis and prognosis, but further studies are needed to unravel all its functions. 
Table 2 Expression and clinical characteristics of SNHG17 in various cancers

\begin{tabular}{|c|c|c|c|c|c|}
\hline Cancer Types & $\begin{array}{l}\text { Sample Size } \\
\text { Tumor:Normal }\end{array}$ & $\begin{array}{l}\text { Expression } \\
\text { Tumor:Normal }\end{array}$ & Clinical Characteristics & Survival Analysis & References \\
\hline Oral squamous cell carcinoma & 40: 40 & UP & $\begin{array}{l}\text { Advanced TNM stages, lymph } \\
\text { node metastasis }\end{array}$ & No description & {$[40]$} \\
\hline $\begin{array}{l}\text { Tongue squamous cell carci- } \\
\text { noma }\end{array}$ & $56: 56$ & UP & $\begin{array}{l}\text { Advanced tumor size and TNM } \\
\text { stages, lymph node metasta- } \\
\text { sis, diagnosis, poorer OS and } \\
\text { prognosis }\end{array}$ & Kaplan-Meier analysis & {$[41]$} \\
\hline $\begin{array}{l}\text { Esophageal squamous cell } \\
\text { carcinoma }\end{array}$ & 126: 126 & UP & $\begin{array}{l}\text { Advanced TNM stages, poorer } \\
\text { prognosis }\end{array}$ & No description & {$[45]$} \\
\hline Lung adenocarcinoma & 50: 50 & UP & $\begin{array}{l}\text { Advanced TNM stages, poorer } \\
\text { OS and prognosis }\end{array}$ & Kaplan-Meier analysis & [49] \\
\hline Breast cancer & 58: 58 & UP & $\begin{array}{l}\text { Advanced TNM stages, lymph } \\
\text { node metastasis, poorer prog- } \\
\text { nosis }\end{array}$ & Kaplan-Meier analysis & {$[12]$} \\
\hline Gastric cancer & 157: 157 & UP & $\begin{array}{l}\text { Advanced TNM stages, lymph } \\
\text { node metastasis, distant metas- } \\
\text { tasis, poorer OS and PFS }\end{array}$ & $\begin{array}{l}\text { Kaplan-Meier analysis, multivari- } \\
\text { ate Cox regression }\end{array}$ & {$[51]$} \\
\hline Gastric cancer & 112: 112 & UP & $\begin{array}{l}\text { Advanced TNM stages and HP } \\
\text { infection, lymph node metasta- } \\
\text { sis, poorer prognosis }\end{array}$ & Kaplan-Meier analysis & {$[11]$} \\
\hline Gastric cancer & 107: 174 & UP & $\begin{array}{l}\text { Advanced TNM stages, invasion } \\
\text { depth, lymph node metastasis, } \\
\text { diagnosis }\end{array}$ & ROC curve & {$[15]$} \\
\hline Colorectal cancer & $56: 56$ & UP & $\begin{array}{l}\text { Advanced tumor size and TNM } \\
\text { stages, lymph node metastasis, } \\
\text { poorer prognosis }\end{array}$ & Kaplan-Meier analysis & [13] \\
\hline Rectal cancer & $46: 46$ & UP & No description & No description & {$[54]$} \\
\hline Colon adenocarcinoma & $45: 45$ & UP & No description & No description & {$[53]$} \\
\hline Hepatocellular carcinoma & $23: 23$ & UP & $\begin{array}{l}\text { Advanced tumor size and } \\
\text { Edmonson-Steiner grades }\end{array}$ & No description & {$[16]$} \\
\hline Hepatocellular carcinoma & $28: 28$ & UP & $\begin{array}{l}\text { Shorter OS and PFS, poorer } \\
\text { prognosis }\end{array}$ & Kaplan-Meier analysis & {$[59]$} \\
\hline Hepatocellular carcinoma & $28: 28$ & UP & $\begin{array}{l}\text { Advanced tumor size and TNM } \\
\text { stages, shorter OS and DFS, } \\
\text { poorer prognosis }\end{array}$ & $\begin{array}{l}\text { Kaplan-Meier analysis, uni- } \\
\text { variate and multivariate Cox } \\
\text { regression }\end{array}$ & {$[60]$} \\
\hline Pancreatic cancer & 30: 30 & UP & No description & No description & {$[62]$} \\
\hline Prostate cancer & 58: 58 & UP & $\begin{array}{l}\text { Advanced TNM stages, poorer } \\
\text { prognosis }\end{array}$ & Kaplan-Meier analysis & {$[66]$} \\
\hline Prostate cancer & $36: 36$ & UP & Poorer prognosis and PFS & Kaplan-Meier analysis & {$[67]$} \\
\hline Renal cell carcinoma & 84: 84 & UP & $\begin{array}{l}\text { Advanced TNM stages, shorter } \\
\text { OS, higher recurrence rate }\end{array}$ & $\begin{array}{l}\text { Kaplan-Meier analysis, uni- } \\
\text { variate and multivariate Cox } \\
\text { regression }\end{array}$ & {$[64]$} \\
\hline Ovarian Cancer & 90: 90 & UP & $\begin{array}{l}\text { Larger tumor size, advanced } \\
\text { FIGO stage and histological } \\
\text { grade, poorer prognosis }\end{array}$ & Kaplan-Meier analysis & {$[70]$} \\
\hline Cervical cancer & 124: 119 & UP & $\begin{array}{l}\text { Diagnosis, advanced tumor size } \\
\text { and FIGO stage, lymph node } \\
\text { metastasis }\end{array}$ & No description & {$[86]$} \\
\hline Melanoma & 148: 148 & UP & $\begin{array}{l}\text { Lymph node metastasis, } \\
\text { advanced tumor stage, poorer } \\
\text { prognosis and OS }\end{array}$ & $\begin{array}{l}\text { Kaplan-Meier analysis, multivari- } \\
\text { ate Cox regression }\end{array}$ & {$[77]$} \\
\hline Osteosarcoma & $5: 5$ & UP & Poorer prognosis and OS & Kaplan-Meier analysis & [18] \\
\hline
\end{tabular}




\begin{abstract}
Abbreviations
InCRNA: Long non-coding RNA; SNHG17: Small nucleolar RNA host gene 17; WHO: World Health Organization; ceRNA: Competing endogenous RNA; miRNA: MicroRNA; MRE: MicroRNA response element; ncRNA: Non-coding RNA; GEPIA2: Gene Expression Profiling Interactive Analysis 2; OSCC: Oral squamous cell carcinoma; RIP: RNA Binding Protein Immunoprecipitation; ChIP: Chromatin immunoprecipitation; TSCC: Tongue squamous cell carcinoma; qRT-PCR: Quantitative real-time quantitative polymerase chain reaction; TNM: Tumour-node-metastasis; OS: Overall survival; ESCC: Esophageal squamous cell carcinoma; EMT: Epithelial-mesenchymal transition; FISH: Fluorescence in situ hybridization; TCGA: The Cancer Genome Atlas; NSCLC: Non-small cell lung cancer; LUAD: Lung adenocarcinoma; BC: Breast cancer; HP: Helicobacter pylori; PFS: Progression-free survival; DSB: DNA double-strand breaks; CRC: Colorectal cancer; GEO: Gene Expression Omnibus; ENCORI: Encyclopedia of RNA Interactomes; HCC: Hepatocellular carcinoma; snoRNA: Small nucleolar RNA; CRPC: Castration resistant prostate cancer; HSPC: Hormone sensitive prostate cancer.
\end{abstract}

\section{Acknowledgements}

Not applicable.

\section{Authors' contributions}

$L M, J G$, and NZ wrote and drafted the manuscript. JW, TX, TL, and XZ prepared the figures and tables. ZW and CW revised and designed the manuscript. All authors read and approved the final manuscript.

\section{Funding}

This work was supported by grants from the National Natural Science Foundation of China (Nos: 82072591, 81871871 to ZW; 81703056 to CW), Key Research and Development plan (Social Development) of the Science and Technology Department of Jiangsu Province (No. BE2019760), the Medical Innovation Team Foundation of the Jiangsu Provincial Enhancement Health Project (No. CXTDA2017021 to ZW), "123" advantageous disciplines, core technologies and "789" excellent talent training plan of the Second Affiliated Hospital of Nanjing Medical University (No. 789ZYRC202090148 to CW).

\section{Availability of data and materials}

Not applicable.

\section{Declarations}

\section{Ethics approval and consent to participate}

Not applicable.

\section{Consent for publication}

Not applicable.

\section{Competing interests}

The authors declare no competing interests.

\section{Author details}

${ }^{1}$ Cancer Medical Center, The Second Affiliated Hospital of Nanjing Medical University, Nanjing 210011, Jiangsu, China. ${ }^{2}$ Department of General Surgery, The Second Affiliated Hospital of Nanjing Medical University, Nanjing 210011, Jiangsu, China.

Received: 6 November 2021 Accepted: 21 February 2022

Published online: 05 March 2022

\section{References}

1. Sung H, Ferlay J, Siegel RL, Laversanne M, Soerjomataram I, Jemal A, et al. Global Cancer Statistics 2020: GLOBOCAN estimates of incidence and mortality worldwide for 36 cancers in 185 countries. CA Cancer J Clin. 2021;71(3):209-49.

2. Soerjomataram I, Bray F. Planning for tomorrow: global cancer incidence and the role of prevention 2020-2070. Nat Rev Clin Oncol 2021
3. Carrera PM, Kantarjian HM, Blinder VS. The financial burden and distress of patients with cancer: understanding and stepping-up action on the financial toxicity of cancer treatment. CA Cancer J Clin. 2018;68(2):153-65.

4. Wu P, Mo Y, Peng M, Tang $T$, Zhong $Y$, Deng $X$, et al. Emerging role of tumor-related functional peptides encoded by IncRNA and circRNA. Mol Cancer. 2020;19(1):22.

5. Zimta AA, Tigu AB, Braicu C, Stefan C, Ionescu C, Berindan-Neagoe I. An emerging class of long non-coding RNA With oncogenic role arises from the snoRNA host genes. Front Oncol. 2020;10:389.

6. Qin Y, Sun W, Wang Z, Dong W, He L, Zhang T, et al. Long non-coding small nucleolar RNA host genes (SNHGs) in endocrine-related cancers. Onco Targets Ther. 2020;13:7699-717.

7. Yang H, Jiang Z, Wang S, Zhao Y, Song X, Xiao Y, et al. Long non-coding small nucleolar RNA host genes in digestive cancers. Cancer Med. 2019;8(18):7693-704.

8. Salmena L, Poliseno L, Tay Y, Kats L, Pandolfi PP. A ceRNA hypothesis: the Rosetta Stone of a hidden RNA language?. Cell 2011;146(3):353-8.

9. Tay Y, Rinn J, Pandolfi PP. The multilayered complexity of ceRNA crosstalk and competition. Nature 2014;505(7483):344-52.

10. Chen $X$, Chen Z, Yu S, Nie F, Yan S, Ma P, et al. Long noncoding RNA LINC01234 functions as a competing endogenous RNA to regulate CBFB expression by sponging miR-204-5p in gastric cancer. Clin Cancer Res. 2018;24(8):2002-14.

11. Han T, Jing X, Bao J, Zhao L, Zhang A, Miao R, et al. H. pylori infection alters repair of DNA double-strand breaks via SNHG17. J Clin Invest. 2020;130(7):3901-18.

12. Du Y, Wei N, Hong J, Pan W. Long non-coding RNASNHG17 promotes the progression of breast cancer by sponging miR-124-3p. Cancer Cell Int. 2020;20:40.

13. Ma Z, Gu S, Song M, Yan C, Hui B, Ji H, et al. Long non-coding RNA SNHG17 is an unfavourable prognostic factor and promotes cell proliferation by epigenetically silencing P57 in colorectal cancer. Mol Biosyst. 2017;13(11):2350-61.

14. Xu T, Yan S, Jiang L, Yu S, Lei T, Yang D, et al. Gene amplification-driven long noncoding RNA SNHG17 regulates cell proliferation and migration in human non-small-cell lung cancer. Mol Ther Nucleic Acids. 2019;17:405-13.

15. Zhang G, Xu Y, Wang S, Gong Z, Zou C, Zhang H, et al. LncRNA SNHG17 promotes gastric cancer progression by epigenetically silencing of p15 and p57. J Cell Physiol. 2019;234(4):5163-74.

16. Ma T, Zhou X, Wei H, Yan S, Hui Y, Liu Y, et al. Long non-coding RNA SNHG17 upregulates RFX1 by sponging miR-3180-3p and promotes cellular function in hepatocellular carcinoma. Front Genet. 2020;11:607636.

17. Zhang YT, Yang GY. LncRNA SNHG17 acts as a ceRNA of miR-324-3p to contribute the progression of osteosarcoma. J Biol Regul Homeost Agents. 2020;34(4):1529-33.

18. Zhao A, Zhao Z, Liu W, Cui X, Wang N, Wang Y, et al. Carcinoma-associated fibroblasts promote the proliferation and metastasis of osteosarcoma by transferring exosomal LncRNA SNHG17. Am J Transl Res. 2021;13(9):10094-111.

19. Li J, Du B, Geng X, Zhou L. IncRNA SNHG17 is downregulated in gestational diabetes mellitus (GDM) and has predictive values. Diabetes Metab Syndr Obes. 2021;14:831-8.

20. Mohamadi M, Ghaedi H, Kazerouni F, Erfanian OM, Kalbasi S, Shanaki $\mathrm{M}$, et al. Deregulation of long noncoding RNA SNHG17 and TTC28-AS1 is associated with type 2 diabetes mellitus. Scand J Clin Lab Invest. 2019:79(7):519-23.

21. Guo F, Wang W, Song Y, Wu L, Wang J, Zhao Y, et al. LncRNA SNHG17 knockdown promotes Parkin-dependent mitophagy and reduces apoptosis of podocytes through Mst1. Cell Cycle. 2020;19(16):1997-2006.

22. Huang $L$, Jiang $X$, Wang Z, Zhong $X$, Tai S, Cui Y. Small nucleolar RNA host gene 1: a new biomarker and therapeutic target for cancers. Pathol Res Pract. 2018;214(9):1247-52.

23. Xu B, Mei J, Ji W, Bian Z, Jiao J, Sun J, et al. LncRNA SNHG3, a potential oncogene in human cancers. Cancer Cell Int. 2020;20(1):536.

24. Chu Q, Gu X, Zheng Q, Guo Z, Shan D, Wang J, et al. Long noncoding RNA SNHG4: a novel target in human diseases. Cancer Cell Int. 2021;21(1):583.

25. Han W, Shi J, Cao J, Dong B, Guan W. Latest advances of long non-coding RNA SNHG5 in human cancers. Onco Targets Ther. 2020;13:6393-403.

26. Li YH, Hu YQ, Wang SC, Li Y, Chen DM. LnCRNA SNHG5: a new budding star in human cancers. Gene. 2020;749:144724. 
27. Wang HS, Zhang W, Zhu HL, Li QP, Miao L. Long noncoding RNA SNHG6 mainly functions as a competing endogenous RNA in human tumors. Cancer Cell Int. 2020;20:219.

28. Zhang S, Qiu D, Xie X, Shen Y. Clinicopathological and prognostic value of SNHG6 in cancers: a systematic review and a meta-analysis. BMC Cancer. 2020;20(1):343.

29. Zhou Y, Tian B, Tang J, Wu J, Wang H, Wu Z, et al. SNHG7: a novel vital oncogenic IncRNA in human cancers. Biomed Pharmacother. 2020;124:109921.

30. Yuan X, Yan Y, Xue M. Small nucleolar RNA host gene 8: a rising star in the targets for cancer therapy. Biomed Pharmacother. 2021;139:111622.

31. Tamang S, Acharya V, Roy D, Sharma R, Aryaa A, Sharma U, et al. SNHG12: an LncRNA as a potential therapeutic target and biomarker for human cancer. Front Oncol. 2019:9:901.

32. Tong J, Ma X, Yu H, Yang J. SNHG 15 : a promising cancer-related long noncoding RNA. Cancer Manag Res. 2019;11:5961-9.

33. Shuai Y, Ma Z, Lu J, Feng J. LncRNA SNHG15: A new budding star in human cancers. Cell Prolif. 2020;53(1):e12716.

34. Gong CY, Tang R, Nan W, Zhou KS, Zhang HH. Role of SNHG16 in human cancer. Clin Chim Acta. 2020:503:175-80.

35. Yang M, Wei W. SNHG16: a novel long-non coding RNA in human cancers. Onco Targets Ther. 2019;12:11679-90.

36. Zhao W, Ma X, Liu L, Chen Q, Liu Z, Zhang Z, et al. SNHG20: a vital IncRNA in multiple human cancers. J Cell Physiol 2019.

37. Parzefall T, Schnoell J, Monschein L, Foki E, Liu DT, Frohne A, et al. PRKCA overexpression is frequent in young oral tongue squamous cell carcinoma patients and is associated with poor prognosis. Cancers (Basel) 2021;13(9).

38. Peng Y, Hu S, Zhang K, Wang Y, Rouzi M, Zhou D, et al. Downregulation of microRNA-130a inhibits oral squamous cell carcinoma proliferation and metastasis via the hippo-YAP pathway. Cancer Manag Res. 2021;13:4829-40.

39. Qiao C, Qiao T, Yang S, Liu L, Zheng M. SNHG17/miR-384/ELF1 axis promotes cell growth by transcriptional regulation of CTNNB1 to activate Wnt/beta-catenin pathway in oral squamous cell carcinoma. Cancer Gene Ther 2021.

40. Tong F, Guo J, Miao Z, Li Z. LncRNA SNHG17 promotes the progression of oral squamous cell carcinoma by modulating miR-375/PAX6 axis. Cancer Biomark. 2021;30(1):1-12.

41. Liu X, Zhang B, Jia Y, Fu M. SNHG17 enhances the malignant characteristics of tongue squamous cell carcinoma by acting as a competing endogenous RNA on microRNA-876 and thereby increasing specificity protein 1 expression. Cell Cycle. 2020;19(6):711-25.

42. Chen W, Zheng R, Baade PD, Zhang S, Zeng H, Bray F, et al. Cancer statistics in China, 2015. CA Cancer J Clin. 2016;66(2):115-32.

43. Zeng H, Zheng R, Zhang S, Zuo T, Xia C, Zou X, et al. Esophageal cancer statistics in China, 2011: estimates based on 177 cancer registries. Thorac Cancer. 2016;7(2):232-7.

44. van Rossum P, Mohammad NH, Vleggaar FP, van Hillegersberg R. Treatment for unresectable or metastatic oesophageal cancer: current evidence and trends. Nat Rev Gastroenterol Hepatol. 2018;15(4):235-49.

45. Wenhu C, Lifang W, Xiaoyan L, Changan Z, Liang S, Hongguang Z, et al. LncRNA SNHG17 regulates cell proliferation and invasion by targeting miR-338-3p/SOX4 axis in esophageal squamous cell carcinoma. Cell Death Dis. 2021;12(9):806.

46. Siegel RL, Miller KD, Fuchs HE, Jemal A. Cancer statistics, 2021. CA Cancer J Clin. 2021;71(1):7-33.

47. Relli V, Trerotola M, Guerra E, Alberti S. Abandoning the notion of nonsmall cell lung cancer. Trends Mol Med. 2019;25(7):585-94.

48. Li W, Zheng Y, Mao B, Wang F, Zhong Y, Cheng D. SNHG17 upregulates WLS expression to accelerate lung adenocarcinoma progression by sponging miR-485-5p. Biochem Biophys Res Commun. 2020;533(4):1435-41.

49. Zhang Z, Yan Y, Zhang B, Ma Y, Chen C, Wang C. Long non-coding RNA SNHG17 promotes lung adenocarcinoma progression by targeting the microRNA-193a-5p/NETO2 axis. Oncol Lett 2021;22(6).

50. Smyth EC, Nilsson M, Grabsch HI, van Grieken NC, Lordick F. Gastric cancer. Lancet. 2020;396(10251):635-48.
51. Chen LL, He J, Qiu XT, Yu J, Wang ZM. The prognostic roles of long noncoding RNA SNHG17 in the patients with gastric cancer. Eur Rev Med Pharmacol Sci. 2019;23(3):1063-8.

52. Biller $\mathrm{LH}$, Schrag D. Diagnosis and treatment of metastatic colorectal cancer: a review. JAMA. 2021;325(7):669-85.

53. Liu J, Zhan Y, Wang J, Wang J, Guo J, Kong D. IncRNA-SNHG17 promotes colon adenocarcinoma progression and serves as a sponge for miR-375 to regulate CBX3 expression. Am J Transl Res. 2020;12(9):5283-95.

54. Huang F, Li H, Qin Z, Wang A, Zhang Y, Guo J, et al. SNHG17 Serves as an oncogenic IncRNA by regulating the miR-361-3p/STC2 axis in rectal cancer. Front Genet 2021;12.

55. Liu Y, Li Q, Tang D, Li M, Zhao P, Yang W, et al. SNHG17 promotes the proliferation and migration of colorectal adenocarcinoma cells by modulating CXCL12-mediated angiogenesis. Cancer Cell Int. 2020;20(1):566.

56. Llovet JM, Zucman-Rossi J, Pikarsky E, Sangro B, Schwartz M, Sherman M, et al. Hepatocellular carcinoma. Nat Rev Dis Primers. 2016;2:16018.

57. Lafaro KJ, Demirjian AN, Pawlik TM. Epidemiology of hepatocellular carcinoma. Surg Oncol Clin N Am. 2015;24(1):1-17.

58. Cox AL, El-Sayed MH, Kao JH, Lazarus JV, Lemoine M, Lok AS, et al. Progress towards elimination goals for viral hepatitis. Nat Rev Gastroenterol Hepatol. 2020;17(9):533-42.

59. Jin-Yu L, Ya-Jing C, Huan-Hui F, Zhan-Li C, Yun-Long W, Jin-E Y, et al. LncRNA SNHG17 interacts with LRPPRC to stabilize c-Myc protein and promote G1/S transition and cell proliferation. Cell Death Dis. 2021;12(11):970.

60. Luo Y, Lin J, Zhang J, Song Z, Zheng D, Chen F, et al. LncRNA SNHG17 contributes to proliferation, migration, and poor prognosis of hepatocellular carcinoma. Can J Gastroenterol. 2021;2021:1-11.

61. Moore A, Donahue T. Pancreatic cancer. JAMA. 2019;322(14):1426

62. Zhao L, Ye J, Lu Y, Sun C, Deng X. IncRNA SNHG17 promotes pancreatic carcinoma progression via cross-talking with miR-942. Am J Transl Res. 2021;13(3):1037-50

63. Xuan Y, Chen W, Liu K, Gao Y, Zuo S, Wang B, et al. A risk signature with autophagy-related long noncoding RNAs for predicting the prognosis of clear cell renal cell carcinoma: based on the TCGA database and bioinformatics. Dis Markers. 2021:2021:8849977.

64. Wu J, Dong G, Liu T, Zhang S, Sun L, Liang W. LncRNA SNHG17 promotes tumor progression and predicts poor survival in human renal cell carcinoma via sponging miR-328-3p. Aging (Albany NY). 2021;13(17):21232-50.

65. Litwin MS, Tan HJ. The diagnosis and treatment of prostate cancer: a review. JAMA. 2017:317(24):2532-42.

66. Zhao H, Dong H, Wang P, Zhu H. Long non-coding RNA SNHG17 enhances the aggressiveness of ( $4-2$ human prostate cancer cells in association with beta-catenin signaling. Oncol Lett. 2021;21(6):472.

67. Wu G, Hao C, Qi X, Nie J, Zhou W, Huang J, et al. LncRNA SNHG17 aggravated prostate cancer progression through regulating its homolog SNORA71B via a positive feedback loop. Cell Death Dis. 2020;1 1(5):393.

68. Bai M, Lei Y, Wang M, Ma J, Yang $\mathrm{P}$, Mou X, et al. Long non-coding RNA SNHG17 promotes cell proliferation and invasion in castration-resistant prostate cancer by targeting the miR-144/CD51 axis. Front Genet. 2020;11:274.

69. Kuroki L Guntupalli SR. Treatment of epithelial ovarian cancer BMJ 2020;371:m3773.

70. Pan X, Guo Z, Chen Y, Zheng S, Peng M, Yang Y, et al. STAT3-induced IncRNA SNHG17 exerts oncogenic effects on ovarian cancer through regulating CDK6. Mol Ther Nucleic Acids. 2020;22:38-49.

71. Zheng ZJ, Liu Y, Wang HJ, Pang WW, Wang Y. LncRNA SNHG17 promotes proliferation and invasion of ovarian cancer cells through up-regulating FOXA1. Eur Rev Med Pharmacol Sci. 2020;24(18):9282-9.

72. Meng C, Zhou JQ, Liao YS. Autophagy-related long non-coding RNA signature for ovarian cancer. J Int Med Res. 2020:48(11):1220770313.

73. Cao S, Li H, Li L. LncRNA SNHG17 contributes to the progression of cervical cancer by targeting microRNA-375-3p. Cancer Manag Res. 2021;13:4969-78.

74. Lapointe S, Perry A, Butowski NA. Primary brain tumours in adults. Lancet. 2018;392(10145):432-46.

75. Ge BH, Li GC. Long non-coding RNA SNHG17 promotes proliferation, migration and invasion of glioma cells by regulating the miR-23b-3p/ ZHX1 axis. J Gene Med. 2020;22(11):e3247. 
76. Li H, LiT, Huang D, Zhang P. Long noncoding RNA SNHG17 induced by YY1 facilitates the glioma progression through targeting miR-506-3p/ CTNNB1 axis to activate Wnt/beta-catenin signaling pathway. Cancer Cell Int. 2020;20:29.

77. Du F, Hou Q. SNHG17 drives malignant behaviors in astrocytoma by targeting miR-876-5p/ERLIN2 axis. BMC Cancer. 2020;20(1):839.

78. Gao H, Liu R, Sun X. STAT3-induced upregulation of IncRNA SNHG17 predicts a poor prognosis of melanoma and promotes cell proliferation and metastasis through regulating PI3K-AKT pathway. Eur Rev Med Pharmacol Sci. 2019;23(18):8000-10.

79. Li M, Shao F, Qian Q, Yu W, Zhang Z, Chen B, et al. A putative long noncoding RNA-encoded micropeptide maintains cellular homeostasis in pancreatic beta cells. Mol Ther Nucleic Acids. 2021;26:307-20.

80. Ge Q, Jia D, Cen D, Qi Y, Shi C, Li J, et al. Micropeptide ASAP encoded by LINC00467 promotes colorectal cancer progression by directly modulating ATP synthase activity. J Clin Invest 2021.

81. Niu L, Lou F, Sun Y, Sun L, Cai X, Liu Z, et al. A micropeptide encoded by IncRNA MIR155HG suppresses autoimmune inflammation via modulating antigen presentation. Sci Adv. 2020;6(21):z2059.

82. Guttman M, Amit I, Garber M, French C, Lin MF, Feldser D, et al. Chromatin signature reveals over a thousand highly conserved large non-coding RNAs in mammals. Nature. 2009;458(7235):223-7.

83. Bhan A, Soleimani M, Mandal SS. Long noncoding RNA and cancer: a new paradigm. Cancer Res. 2017;77(15):3965-81.

84. Michalak EM, Burr ML, Bannister AJ, Dawson MA. The roles of DNA, RNA and histone methylation in ageing and cancer. Nat Rev Mol Cell Biol. 2019;20(10):573-89.

85. Sas-Chen A, Thomas JM, Matzov D, Taoka M, Nance KD, Nir R, et al. Dynamic RNA acetylation revealed by quantitative cross-evolutionary mapping. Nature. 2020;583(7817):638-43.

86. Mansour MA. Ubiquitination: friend and foe in cancer. Int J Biochem Cell Biol. 2018;101:80-93.

87. Barile L, Vassalli G. Exosomes: therapy delivery tools and biomarkers of diseases. Pharmacol Ther. 2017;174:63-78.

88. Kok VC, Yu CC. Cancer-derived exosomes: their role in cancer biology and biomarker development. Int J Nanomedicine. 2020;15:8019-36.

89. Regimbeau M, Abrey J, Vautrot V, Causse S, Gobbo J, Garrido C. Heat shock proteins and exosomes in cancer theranostics. Semin Cancer Biol 2021.

90. Yu W, Hurley J, Roberts D, Chakrabortty SK, Enderle D, Noerholm M, et al. Exosome-based liquid biopsies in cancer: opportunities and challenges. Ann Oncol. 2021;32(4):466-77.

91. Guo X, Lv X, Ru Y, Zhou F, Wang N, Xi H, et al. Circulating exosomal gastric cancer-associated long noncoding RNA1 as a biomarker for early detection and monitoring progression of gastric cancer: a multiphase study. JAMA Surg. 2020;155(7):572-9.

92. Lin $L Y$, Yang $L$, Zeng $Q$, Wang $L$, Chen $M L$, Zhao ZH, et al. Tumor-originated exosomal IncUEGC1 as a circulating biomarker for early-stage gastric cancer. Mol Cancer. 2018;17(1):84.

93. Zhao R, Zhang $Y$, Zhang $X$, Yang $Y$, Zheng $X$, Li X, et al. Exosomal long noncoding RNA HOTTIP as potential novel diagnostic and prognostic biomarker test for gastric cancer. Mol Cancer. 2018;17(1):68.

94. Tan SK, Pastori C, Penas C, Komotar RJ, Ivan ME, Wahlestedt C, et al. Serum long noncoding RNA HOTAIR as a novel diagnostic and prognostic biomarker in glioblastoma multiforme. Mol Cancer. 2018;17(1):74.

95. Winkle M, El-Daly SM, Fabbri M, Calin GA. Noncoding RNA therapeutics challenges and potential solutions. Nat Rev Drug Discov 2021.

\section{Publisher's Note}

Springer Nature remains neutral with regard to jurisdictional claims in published maps and institutional affiliations. 